\title{
The Study on the Circuit Design and Implementation of the Low Voltage Variable Frequency Speed Regulating Device
}

\author{
Ying Zhou ${ }^{1, a}$ \\ ${ }^{1}$ Chongqing College of Electronic Engineering Chongqing 401331 China \\ azhouying_cq@163.com
}

Keywords: Low voltage variable frequency speed regulating device, Circuit design, Implementation

\begin{abstract}
The electrical products industry is always the important industry in the field of industrial, is the basic industry of the level of economic development in our country. Therefore, with the rapid development of economy, it needs continually to improve some infrastructure resource allocation level of the electronic instrument and equipment of electric industry, and continuously research and development the industrial development of new technology products, thus it can improve the development the status quo of the electronic electrical industry. This paper will design a set of circuit, including current, voltage, speed sampling circuit and filter circuit. The sampling of the experimental results shows that the designed circuit has simple structure, high precision, fast response speed, which can meet the requirements of a new generation of motor variable frequency speed regulation system.
\end{abstract}

\section{Introduction}

The low voltage variable frequency speed regulating device (hereinafter referred to as the frequency conversion device) is a commonly used ac motor speed control device, is made up of general inverter (hereinafter referred to as the frequency converter), equipment to suppress harmonic wave, primary and secondary electrical equipment cabinet device, consisting of a generally independent arrangement in power distribution room. Frequency control of motor speed hardware system based on DSP core control circuit, main circuit form for typical three intersection has a alternating voltage source inverter circuit, rectifier part by three-phase uncontrolled rectifier ac/dc conversion module; Inverter part adopts intelligent power module (IPM) as inverter main switching device, control stability, with protective function, improve the reliability of the inverter. Its main components include rectifier circuit, filter circuit, inverter circuit, sampling circuit, current, voltage, speed, power circuit, etc.

\section{The Principle and Commonly Used Functions of the Inverter}

The principle of the frequency converter. The frequency control of motor speed and energy saving. According to water pump working principle of a power is proportional to the flow rate and rotating speed, power and speed of the direct, lift and is proportional to the square of the speed, the efficiency of the pump keep certain, when adjusting flow down, speed is proportional to drop, the established power relations. (2) The power factor compensation function. Reactive power is easy to cause equipment heat and increase the line loss, power factor lower will make active power is reduced, resulting in a large number of power consumption, reduce the use of the equipment efficiency, waste is serious. Device frequency conversion governor to improve the power factor, reduce reactive loss. (3) The soft start saving energy. Motor generally to Y/D start and direct start, the starting current is equal to the rated current of 4 to 7 times; it needs both high capacitances, also easy to affect the service life of the motor. Inverter can use soft start make greatly reduce the startup current, reduces the requirement of electric capacity, reduce the impact to the grid, extend the life of the equipment.

The commonly used functions of the inverter. The overload protection function. This function can effectively protect the motor to make it not easy to burn. Motor run in low amount of its poor heat dissipation lead to serious, electric heating temperature exceed the rating. Inverter has the 
function of electronic thermal protection which under the different operation frequency curve has a corresponding protection, the lower the frequency, the continuous running time is short, to effectively protect the motor. (2) The acc function. Frequency converter of the acc is actually from a stable state to another stable state, in general, in guarantee under the condition of current is lower than the rated current, as far as possible to reduce acc time. Among the common way of acc are: s-shaped way, half s-shaped way, a linear relationship between frequency and time. Of course need according to the specific situation to choose the right means of acc.

\section{The Application of the Variable Frequency Speed Control Technology}

The variable frequency speed regulation technology is first appeared in the $1980 \mathrm{~s}$, with the development of science and technology, the emergence of the technology to industrial production into the new period, for the human productivity has played a huge role in promoting. Variable frequency speed regulation technology is mainly composed of the following several parts, each of these components play to their respective functions and has an important role.

(1) The adaptive motor unit model. This unit are the important components, in the specific application, its main function is to input the current and voltage of the motor, thus to identify the basic parameters of motor. According to the motor model, it has a very important role, and is the key for direct torque control unit. Frequency control technology in industry application, usually when the rotate speed control precision is more than $0.5 \%$ of the time, can use the closed loop speed to feedback, and finally meet application requirements. (2) The torque and flux comparator. The comparator is reference value and feedback value comparison respectively, once every $20 \mathrm{~ms}$ for comparison. After contrast, sluggish in the function of the controller is used to state or torque output field, and then will be able to timely grasp the magnetic field and torque, so as to provide important basis for targeted measures. (3) The pulse optimization selector. Usually choose Cvclone11EP2C5Q208C8 chip to the information processing, to complete the selection, need to design OFDM signal source, but also write circuit is composed of five modules, each module has different functions, including the function of D/A, the buffer module, insert the cyclic prefix, FFT, constellation mapping. It can use OFDM signal simulation approach to the function of these modules for validation. The next job is to complete the design of the OFDM signal source, work content for the FPGA hardware and software simulation validation. Must recognize the electrolytic capacitor has a capacity of itself has strong discreteness, the existence of this feature is likely to cause them to inherit the unequal voltage condition, so as to cause adverse effect to the whole system, then you need to take some measures to this kind of situation to make the necessary improvement and optimization of the final will be discrete may cause adverse effects to eliminate. Commonly used processing methods: beside each capacitor in parallel an equal pressure resistance of the resistor. In addition, in order to protect the safety of the rectifier circuit to prevent burn, can suppress the surge current in the circuit increase method.

\section{The Circuit Design and Implementation of the Low Voltage Variable Frequency Speed Regulating Device}

The design of main circuit. In operation in the process of the design of main circuit is crucial for the design of circuit technology, people are generally adopt inverter circuit. With the current type inverter, the inverter circuit part of intermediate dc link voltage and load. And mesh _ this combination can make the form more clear, and you can also proper debug according to the actual situation, its another advantage is the main circuit power factor is higher. Consists of four double module inverter circuit, the four double unit module can control A series of variable voltage variable frequency activity. In the process of using capacitor adopts $3000 \mathrm{uF} / 450 \mathrm{v}$, it as an energy storage element in the circuit, constitutes the voltage type inverter, and to complete its designated function and task. The change of the IGBT module signal is controlled by the A T89C 51 single chip microcomputer, in the form of PW M technology, realization of variable voltage and variable frequency. The main circuit diagram is shown in figure 1. 


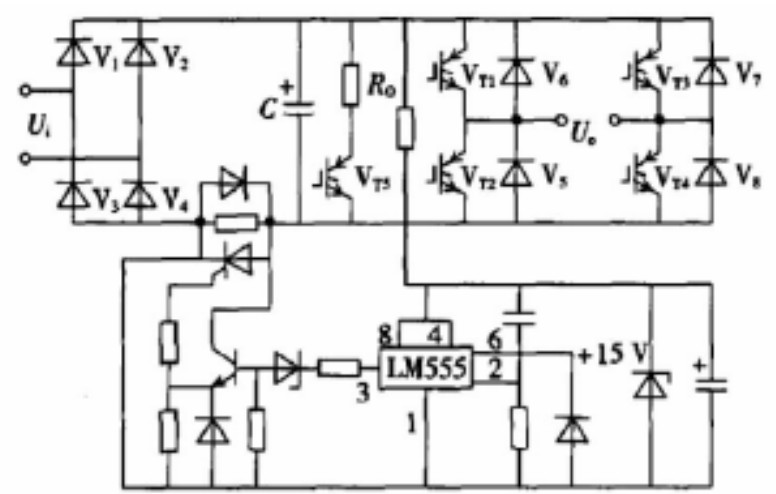

Fig. 1 the main circuit

IGBT driver design. Two unit module, IGBT is belong to the voltage driving element, one of the capacitive input impedance exists in overall structure, thus driving circuit of IGBT high demands are put forward. As a result of the drive in the initial resistance is small, so you can along the space before and after the corresponding increase scope, so the energy dissipations of the IGBT switch will be less. Pressure drop increase state of IGBT and switching loss is reduced, often against load short circuit protection and security, so the actual voltage general as $15 \mathrm{v}$. when shut off, capacitance should be in the state of discharge, in the negative bias voltage on the need to add at this time, usually to keep voltage value can in - $5 \mathrm{v}$. According to the information above, it uses EXB841 thick film, in the design of IGBT type high speed driving circuit.

The speed sampling circuit design. The motor variable frequency speed regulation system requires high precision of speed sampling device, to be able to real-time processing and speed feedback signal. The author adopts the high precision magnetic encoder as detecting element, motor rotation speed, magnetic encoder output pulse signal after toning, two road connected to DSP orthogonal decoding (QEP) and capture unit on the pin, and can complete the detection of DSP to motor speed.

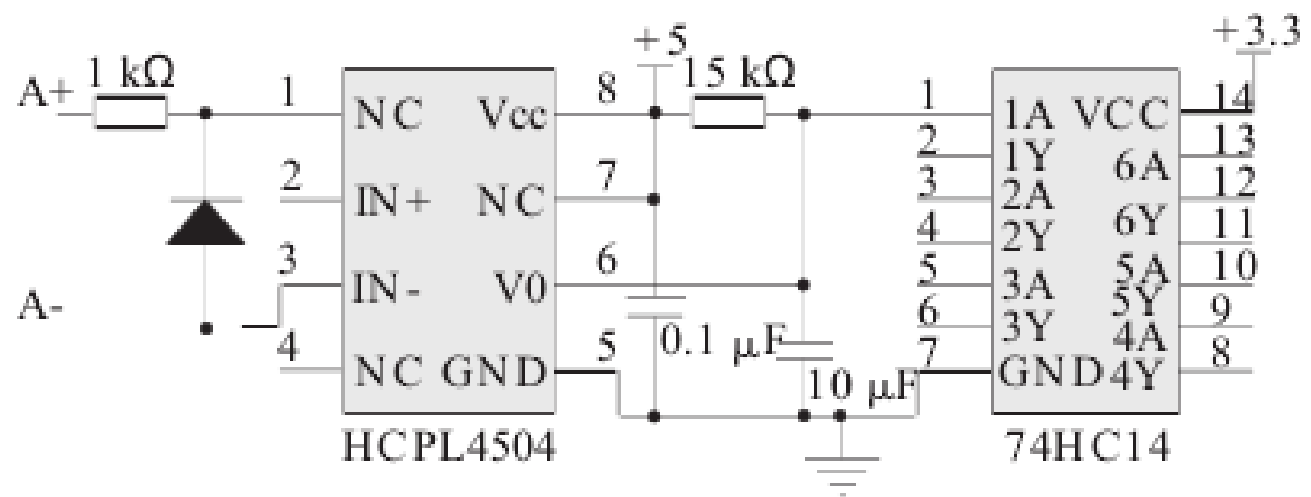

Fig. 2 the Speed Sampling Circuit Diagram

The filter circuit design. From the current and voltage sensor output signal after a series of conditioning ultimately need to be converted to digital signals. In front of the signal collection, external circuit interference may affect the signal gathers which need. The author chooses TI production TLC14C, the chip is a fourth order butterwort active low-pass filter, the filter characteristic is cut than frequency stability and the stability of the clock frequency. Clock frequency and cut-off frequency ratio of 100:1, that is $f_{c}=f_{\text {clock }} / 100$, Cut-off frequency range can be set to $0.1 \mathrm{~Hz}-30 \mathrm{kHz}$, error is less than $\pm 1 \%$, an external clock frequency depends on the foot 1 and 2 feet of resistance and capacitance.

$$
f_{\text {clock }}=\frac{1}{1.69 R_{55} C_{33}}
$$

In the equation, if known $f_{c}$, we can find out the $R_{55}, C_{33}$. 


\section{The Sampling Circuit Experiment of the Low Voltage Variable Frequency Speed Regulation System}

For general frequency converter, single chip microcomputer frequency range is very important. Like the daily use of household appliances, its internal float is equipped with motor load; the motor load can for thermostat control home appliances. So we can use temperature sensors to measure the temperature outside, when the temperature sensor detects the external environment temperature reach the set point temperature, it will output low frequency voltage, on the contrary, when the sensor measurement to the environment temperature is higher than set temperature, it will output high frequency voltage, can reach $80-100 \mathrm{~Hz}$ between the highest frequency. This frequency automatic change is achieved by designing SCM and complete.

1) By the current sampling circuit of the experimental data showed the current waveform similar to sine, period and amplitude are accord with actual.

2) The voltage sampling circuit of the input voltage of $380 \mathrm{~V}$ three-phase alternating current, dc voltage of rectifier, filter circuit, DSP internal reading and the voltmeter is obtained by the experimental error of the measured value is about directly, meet the system accuracy requirement.

3) The given in motor speed of $600 \mathrm{r} / \mathrm{min}$, through the speed sampling circuit of the motor speed tracking performance experiment, and the DSP compares the internal reading and the speed meter readings, results show that the error can be kept within plus or minus $5 \%$.

\section{Summary}

Under normal circumstances, the use of single-chip microcomputer control frequency converter, the cost is very low, and has simple circuit structure, the advantages of high reliability and good real-time, single-phase asynchronous motor frequency control of motor speed, which will be used to have wide practical prospect. So I can foresee, in the future such as low cost, power saving ability strong market development and popularization of home-made frequency converter space will be very broad. Not only that, popularization and application of the control frequency converter is also very good complied with the trend of The Times in today's world energy conservation and environmental protection.

\section{References}

[1] W.L. Yang, T.B. Jang. Hardware design of digital AC servo system based on DSP2812. 2010 International Conference on Intelligent Computing and Integrated Systems. 2010(10).

[2] Derdiyok, Adnan, Güven, Mustafa K., Rehman, Habib-Ur, Inanc, Nihat, Xu, Longya. Design and implementation of a new sliding mode observer for speed-sensor less control of induction machine. IEEE Transactions on Industrial Electronics. 2012(08).

[3] Seo, J.H., Choi, C.H., Hyun, D.S.A new simplified space-vector PWM method for three-level inverters. IEEE Transactions on Power Electronics. 2011(04).

[4] Casadei, Domenico, Serra, Giovanni, Tani, Angelo. Implementation of a direct torque control algorithm for induction motors based on discrete space vector modulation. IEEE Transactions on Power Electronics. 2012(11).

[6] Telford, Dwayne, Dunnigan, Matthew W.,Williams, Barry W. Adaptive high bandwidth current control for induction machines. IEEE Transactions on Power Electronics. 2013(08). 